\title{
IN DEFENSE OF THE GOLD STANDARD: \\ SOME THOUGHTS ON MICHAEL BROOKS' ESSAY ON ONLINE TEACHING
}

\author{
Donn Neal \\ Retired Historian \\ Pittsburgh, PA
}

Perhaps it is no surprise that someone like me, a retired faculty member at a liberal arts college, would wince his way through the essay on online courses that appears in this issue of Teaching History. But despite my personal skepticism about such courses, my response to that essay is less a critique or a rebuttal of it than it is a passionate defense of what I regard as the gold standard of higher education: the venerable, valuable, but now seemingly vulnerable tradition of a teacher-led, oncampus, classroom-based, interpersonal education that has served us so well for so long. It behooves us to think about how invaluable the several elements and attributes of this gold standard are before we send it packing, because, if we do, we will be hard pressed to bring it back.

I am no Luddite (hey, I too have a smart phone). Neither am I naïve or foolish enough to think that all online, computer-based, distance learning is invalid or inappropriate. Nor do I think that the teaching and learning model I revere is the only one teachers should use. My own experience in a dozen years of teaching involved experimenting with a variety of models. Then, I helped to devise and lead a consortial program that assisted college faculty members to rethink and refresh their teaching strategies and skills and that emphasized having different arrows in one's quiver for different situations. After that, overseeing the creation of a competency-based certification program for a national professional society afforded me an opportunity to understand how training exercises can be a key component in learning. Finally, serving for a number of years as the director of an education and training program for a Federal agency brought me a deeper sense of how both of these teaching and learning processes can work together harmoniously when used appropriately.

But all of these experiences, while exposing me to and helping me to appreciate a broader panoply of learning styles and formats, also strengthened my affection and appreciation for the gold standard I have described. To paraphrase an advertisement I recently saw: Interactive classroom teaching sessions led by a skilled professional do not just set the bar for successful teaching, they are the bar when it comes to inculcating and honing the critical-thinking tools and habits that enable a mind to survive and succeed, especially in an information-laden, rapidly changing, and multi-voiced environment. We need more of these opportunities, not fewer.

Of course, the gold standard I describe is not the only path to learning. Studying on one's own obviously has its own special place at the center of an education. Two or more people cannot read a book together, at least for long; joint research is a tricky 
beast to master; and group projects are a different species altogether. And thinking things through in the quiet of one's own head when new ideas come along, and again in moments of retrospection, will always be the most important intellectual activity we can engage in.

At some point, though, education must become a shared experience. Confining larger and larger swaths of learning to passive or solitary study isolates individuals from the greater energy and stimulation of communal learning. It is the confluence of disparate attitudes and minds, of a multiplicity of interests and intellects, that sparks the sort of learning environment that one admires and envies, not only on campuses but in such other give-and-take exercises as corporate board meetings, political strategy sessions, advertising agency brainstorming, medical conferences, musical collaborations, and similar situations where the principal goals are sharing and evaluating information, insights, and inspirations while building a capacity to do these things even better.

So in our enthusiasm to explore and exploit the very real potential of online methodologies and experiences (a not-surprising by-product of a trendy and devicedependent society that is also eager to pare personnel costs to the bone), let's not carelessly discard the tried and true teaching and learning experiences we know can work well when they are done right.

In a purely instructional sense, for me that means the small Socratic-like seminar-a teaching revolution in its own time, of course, though hardly the most economical model in a curriculum dominated by dollars. I am also a fan of the somewhat larger class-discussion model (say, 15-40 participants), which has both strengths and weaknesses when compared to the classic, more intimate seminar. In my view, even the traditional didactic lecture - better yet, the partially didactic one that includes considerable directed discussion - has considerable merit when efficiency of delivery of information is preferred and when creative techniques introduce elements of the kinds of discussions employed with smaller numbers.

In my view, nothing can fully replace the small (we can debate the exact size) group's immediate give and take of information and opinions; the non-verbal responses ranging from raised eyebrows to stifled yawns to the gleam of realization; the infectious joy of grasping someone else's incisive point as it is spoken; the collective coalescence around a consensus arrived at after intense effort (the collective disagreement is no less a victory); the testing of wits and half-baked ideas in a setting where no one has all the answers but all have an obligation to strive for them. Teaching is helping students to learn, from one another as often or as much as from the instructor, and I mean as people rather than as ephemeral electronic strangers.

These vehicles work so well because they develop the skills of critical thinking. They echo, encourage, enable, and enhance the central thrust of a liberal education, which is awakening the ability and honing the capacity to analyze, acquire, and assimilate a torrent of new information; the ability to articulate and knead complex and 
widely varying concepts into a larger construct; the capability to marshal evidence to support or challenge an opinion; and, yes, the skill to make sound arguments for and against propositions put forward by others. These vehicles do that work by having individuals engage with one another in a series of immediate and multi-party discussions, testing their own beliefs and the ideas of others in company with other, critical-thinking individuals.

An incidental but not significant by-product of campus-based educational exercises designed to bring people together into distinct groups is the spirit of joint endeavor that can emerge and develop as a mixed body of students get acquainted and work together, over time, to think as a group about an assigned topic or to explore and master a challenging body of work. Such an education is not just richer and more satisfying on a personal level but lays a good foundation for the way much of society functions today. Moreover, a predominantly on-campus, group-based learning journey can easily be augmented with certain on-line learning opportunities of special merit that, quite literally, widen horizons. I am less sanguine that a mixture reversing these proportions would be as successful.

And let's not overlook the (sometimes superior!) pre- and post-classroom discussions among students and with the instructor. There is ample evidence to suggest that the professional- - and personal-growth of students outside of their classrooms can be every bit as significant as what happens inside those rooms. Learning occurs all over a campus, whether it is a bucolic one spread over many acres or a vertical one plunked down in the middle of a city. Moreover, the personal connections a student makes in on-campus experiences can influence and enrich an entire lifetime, not just one's intellectual development. A good discussion thus is an adventure that begins before and continues beyond a single class session, and this is more likely on a campus dedicated to education than anywhere else.

A unique value is derived from a concentrated, immersive focus on a topic or set of related topics, perhaps on a provocative question to be devised or answered in company with others of diverging views. It often begins with a deceptively simple question: "So, after all that you have read, how should we view Andrew Jackson?" Or, "Was FDR's managerial approach the right one for the circumstances of the Great Depression? What effects of his leadership style do we still feel today, and is it still an appropriate approach?" Or, "Thinking about the kinds of reasons people had for migrating to America, do we still see those impulses in today's migration movements?" And so the adventure begins. Such a focus is far superior to having individual students posting and reading comments on imaginary discussion boards or emailing responses now and then during their busy lives, as time or a job or traffic signals permit.

In sum, well-taught and freewheeling discussion courses are the essence of, perhaps even a microcosm of, what the best college-level experience can be: a chance--heavily subsidized by society, it bears noting-- to work together to confront, 
delve deeply into, and debate essential questions about various aspects of the human experience. There should be more, not fewer, courses with these attributes.

Do the teaching and learning models I am saluting here lack in the convenience and sense of accelerated progress that online learning promises? Yes, but they offer instead time for contemplation and the dynamic of many minds with different perspectives joining to examine - and debate - the same topic. Are these models laborintensive, and thus fairly expensive? Yes, and thank goodness they are: That is the justifiable price for having the complete, personal attention of a well-prepared and skillful mentor. Do these models lack technical wizardry? Only if you are thinking of machines: Real wizardry comes in the form of the miracles of inspiration and comprehension a good instructor and bright students can pull from an hour of intensive and wide-ranging conversation that follows putting a stimulating topic into play.

I close with a caution: Just because it is now possible to drive a vehicle and send texts at the same time, it is not necessarily right or wise to do so. Similarly, I suggest, just because it is possible to design online courses that emulate some of the characteristics of traditional, interpersonal classroom courses, it is not necessarily right or wise to do that. (I recently saw an advertisement promising a nursing degree to be taught "entirely online.") The gold standard of teaching and learning that has served us for generations should not be abandoned just because there now are some more convenient, trendier, and (perhaps) cheaper alternatives.

So let's not deprive ourselves - and, more importantly, our students-of the alltoo-few opportunities that the college years provide to take part in the range of interactive, teacher-led models that a campus-based person-to-person education offers. There will be plenty of occasions, later, for our students to learn at the computer monitors in their work stations or in their palms. 